\title{
Effects of crop residue managements and tillage practices on variations of soil penetration resistance in sloping farmland of Mollisols
}

\author{
Yijiao Wang, Jinyou Qiao, Wenyi Ji, J ian Sun, Dongxu Huo, Yupeng Liu, Haitao Chen* \\ (College of Engineering, Northeast Agricultural University, Harbin 150030, China)
}

\begin{abstract}
Soil penetration resistance (SPR) is one of the major indicators of soil physical properties. Crop residue managements, tillage practices and their interactions exert significant effects on the SPR. However, rare information is available in the sloping farmland of Mollisols. Field experiments were conducted to investigate the variations of the SPR as affected by crop residue managements and tillage practices on the sloping land in Northeast China from 2015 to 2019 . The split-plot experiment was arranged with two crop residue managements (removed, REM and retained, RET), and three tillage practices (no tillage, NT; rotary tillage, RT; plow tillage, PT). SPR data in $0-80 \mathrm{~cm}$ soil depth was measured at the end of harvest of maize monoculture. Results showed that the two crop residue managements induced significant variations in the SPR at 0-15 cm, 15-30 cm and 0-80 cm soil depths under NT, RT, and PT treatments, respectively. In comparison with RET treatment, the average values of the SPR under REM treatment were $10.9 \%$ and $8.9 \%$ higher in $45-60 \mathrm{~cm}$ and $60-80 \mathrm{~cm}$ soil depths, respectively. The average values of the SPR under PT treatment were $12.4 \%$ and $14.1 \%$ lower in $0-15 \mathrm{~cm}$ soil depth, and $23.9 \%$ and $10.4 \%$ lower in $15-30 \mathrm{~cm}$ soil depth than those under NT and RT treatments. However, the average value of the SPR under PT treatment was $11.2 \%$ and $22.0 \%$ higher in $60-80 \mathrm{~cm}$ soil depth than those under NT and RT treatments, respectively. The SPR generally decreased with the slope position declined in the deeper soil depth (except for the NT + RET treatment). The findings from this research can provide a scientific reference for the establishment of rational cultivation and the sustainable development of productivity on the sloping land of Mollisols in cold regions.
\end{abstract}

Keywords: soil penetration resistance, crop residue management, tillage practice, slope position, soil depth, Mollisols DOI: $10.25165 /$ j.ijabe. 20221501.6526

Citation: Wang Y J, Qiao J Y, Ji W Y, Sun J, Huo D X, Liu Y P, et al. Effects of crop residue managements and tillage practices on variations of soil penetration resistance in sloping farmland of Mollisols. Int J Agric \& Biol Eng, 2022; 15(1): $164-171$

\section{Introduction}

Appropriate soil structure and a fertile environment are the basic conditions for ensuring good quality and high yield of crops, and are an important guarantee for sustainable soil use. A key factor in evaluating soil quality is soil penetration resistance (SPR), which is one of the major indicators of the physical properties of soil $^{[1,2]}$. Seedling emergence, nutrient absorption, root morphology, and crop yield are significantly affected by the $\mathrm{SPR}^{[3-5]}$. The SPR is influenced by factors such as the tillage system, machine compaction, and soil water content ${ }^{[6-9]}$.

The Mollisol region of the world makes an important contribution to the maize production base. The amount of maize stover has increased significantly with the increase of maize planting area and yield. Subsequently, the removal or large-scale

\section{Received date: 2021-02-14 Accepted date: 2021-10-24}

Biographies: Yijiao Wang, PhD candidate, Senior Engineer, research interest: production and management of agricultural mechanization, Email: wangyijiao@neau.edu.cn; Jinyou Qiao, PhD, Professor, research interest: production and management of agricultural mechanization, Email: qiaojinyou@163.com; Wenyi Ji, Master, Professor, research interest: agricultural machinery, Email: jwy730306@163.com; Jian Sun, PhD candidate, research interest: production and management of agricultural mechanization, Email: dnsunjian@163.com; Dongxu Huo, Master, research interest: production and management of agricultural mechanization, Email: 2745293589@qq.com; Yupeng Liu, Master, research interest: production and management of agricultural mechanization, Email: 976810696@qq.com.

*Corresponding author: Haitao Chen, $\mathrm{PhD}$, Professor, research interest: technical equipment of agriculture and biomass materials. College of Engineering, Northeast Agricultural University, Harbin 150030, China. Tel: +86-15504508358, Email: htchen@neau.edu.cn. combustion of crop residues results in a serious waste of straw resources or increased air pollution as a result of mass open burnings of crop residues ${ }^{[10]}$. Crop residue returning can effectively increase soil organic matter content, reduce chemical fertilization input, and mitigate environmental pollution ${ }^{[10-12]}$. Furthermore, retained crop residues play a positive role in maintaining the soil water condition, increasing the microbial activity and growth, and controlling the soil runoff and erosion ${ }^{[13-15]}$ In addition to improving the soil quality, residue returning also benefits the growth and yield of crops ${ }^{[16-18]}$. Widely distributed sloping farmland is an important cultivated land resource but it is more susceptible to soil erosion, particularly under inappropriate soil managements in the Mollisol region ${ }^{[19-22]}$. Over-cultivation of modern agricultural production on sloping farmland has escalated the risk of increasing the soil degradation, thinning of the black soil layer, thickening and hardening of the plough pan, and weakening of the structural stability.

Some studies have been conducted to study the effects of crop residue managements and tillage practices on the $\operatorname{SPR}^{[1,18,23]}$. However, these studies mainly focused on the effects of the vertical and horizontal directions of the soil profile on the $\operatorname{SPR}^{[24,25]}$. Few systematic studies have been conducted on the variations of the SPR as affected by residue distributions and soil statuses caused by crop residue managements and tillage practices, particularly at different slope positions in the deeper soil depth.

In Northeast China, the slopes of Mollisols provide major farmland for maize production, and for crop residue management, diverse methods of maize stover returning to the field have been used after harvest. It was hypothesized that both crop residue 
managements and tillage practices may have significant effects on the SPR due to varied slope positions. Therefore, the purpose of this research was to systematically investigate the effects of crop residue managements and tillage practices on the SPR in different soil depths of sloping land as well as to prevent the negative effects of SPR at particular slope positions.

\section{Materials and methods}

\subsection{Experimental field}

A five-year field experiment was conducted from April 2015 to October 2019 at Xiangyang Experimental Farm of the Northeast Agricultural University $\left(45^{\circ} 46^{\prime} \mathrm{N}, 126^{\circ} 55^{\prime} \mathrm{E}\right)$ in Harbin, China. The farm is located in the southeast of the Songnen Plain, with a continental monsoon climate. The annual average precipitation ranges from 500 to $600 \mathrm{~mm}$, and most rain occurs from May to
September. The annual average temperature is approximately $3.6^{\circ} \mathrm{C}$, annual average daylight is approximately $2500 \mathrm{~h}$, and annual frost-free season ranges from 135 to $140 \mathrm{~d}$. Details of the monthly mean temperature and rainfall during the experimental period are provided in Figure 1. Test plots were located on the relatively gentle east slope at approximately $3^{\circ}$. Maize monoculture was implemented from 2015 to 2019 growing seasons and maize variety Hezhong11 was planted. The average amount of maize stover residue retained in the tested plots was approximately $0.95 \mathrm{~kg} / \mathrm{m}^{2}$ during the experimental years. The field was under the same conventional tillage treatment for many years before the start of the experiment. The mean SPR value in a depth of $0-40 \mathrm{~cm}$ was $2.12 \mathrm{MPa}$. The test soil was silty clay loam Mollisols and its physical and chemical properties are listed in Table 1.

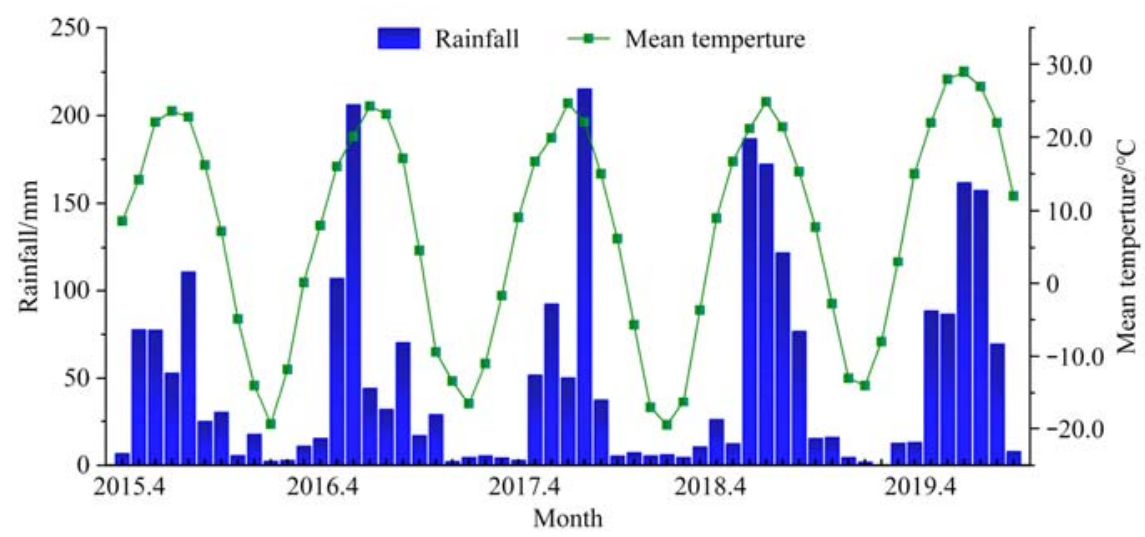

Figure 1 Monthly mean temperature and rainfall during the experimental period

Table 1 Physical and chemical properties of test soil ${ }^{[26]}$

\begin{tabular}{lc}
\hline \multicolumn{1}{c}{ Parameter } & Value \\
\hline Soil organic matter $/ \mathrm{g} \cdot \mathrm{kg}^{-1}$ & 24.5 \\
Available phosphorus $/ \mathrm{mg} \cdot \mathrm{kg}^{-1}$ & 20.5 \\
Available potassium $/ \mathrm{mg} \cdot \mathrm{kg}^{-1}$ & 100 \\
Ammonium nitrogen $/ \mathrm{mg} \cdot \mathrm{kg}^{-1}$ & 32.5 \\
Nitrate nitrogen $/ \mathrm{mg} \cdot \mathrm{kg}{ }^{-1}$ & 14.3 \\
Moisture content $\%$ & 36.3 \\
$\mathrm{pH}$ & 6.03 \\
\hline
\end{tabular}

\subsection{Experimental design and treatments}

The experiment was arranged in a split-plot design, which was implemented in strips from top to bottom and tilled along the slope.
Three tillage practices were used in the main plots: no tillage (NT), rotary tillage (RT), and plow tillage (PT). Two crop residue managements were used as subplots: removed (REM) and retained (RET). Each treatment had three replicates. The detailed information of each treatment is shown in Table 2. Experimental plots $\left(20 \mathrm{~m} \times 5.2 \mathrm{~m}\right.$ with a total area of $\left.104 \mathrm{~m}^{2}\right)$ of each treatment strip were set at the upper, middle and lower slope positions. The plots between adjacent slope positions were placed at intervals of $22 \mathrm{~m}$. The maize was planted in early May each year with a ridge spacing of $65 \mathrm{~cm}$ and harvested in October. The planting density, fertilizer application rate, and field management followed local agricultural practice for all treatments.

Table 2 Workflow of each treatment

\begin{tabular}{|c|c|c|c|}
\hline Abbreviation & Tillage practice & Crop residue management & Workflow \\
\hline $\mathrm{NT}+\mathrm{REM}$ & No tillage & Crop residues removed & Crop residues were removed after the maize was harvested and a no-till seeder sowed seeds. \\
\hline NT+RET & No tillage & Crop residues mulched & $\begin{array}{l}\text { Crop residues were crushed when the maize was harvested. A no-till seeder sowed seeds and } \\
\text { the soil surface was mulched with crop residues. }\end{array}$ \\
\hline $\mathrm{RT}+\mathrm{REM}$ & Rotary tillage & Crop residues removed & $\begin{array}{l}\text { Crop residues were removed after the maize was harvested. Rotary tillage to a depth of } 12- \\
15 \mathrm{~cm} \text { was done with a rototiller and a conventional seeder sowed seeds. }\end{array}$ \\
\hline $\mathrm{RT}+\mathrm{RET}$ & Rotary tillage & Crop residues shallow mixed & $\begin{array}{l}\text { Crop residues were crushed when the maize was harvested. Rotary tillage to a depth of } 12- \\
15 \mathrm{~cm} \text { was done with a rototiller, crop residues were shallowly mixed in the } 0-15 \mathrm{~cm} \text { soil } \\
\text { depth, and a conventional seeder sowed seeds. }\end{array}$ \\
\hline $\mathrm{PT}+\mathrm{REM}$ & Plow tillage & Crop residues removed & $\begin{array}{l}\text { Crop residues were removed after the maize was harvested. The soil was deeply ploughed to } \\
\text { a depth of } 25-30 \mathrm{~cm} \text { using a moldboard plow, harrowed twice with a disc harrow, and a } \\
\text { conventional seeder sowed seeds. }\end{array}$ \\
\hline $\mathrm{PT}+\mathrm{RET}$ & Plow tillage & Crop residues deeply buried & $\begin{array}{l}\text { Crop residues were crushed when the maize was harvested. The soil was deeply ploughed to } \\
\text { a depth of } 25-30 \mathrm{~cm} \text { using a moldboard plow and harrowed twice with a disc harrow. Crop } \\
\text { residues were buried in the } 0-30 \mathrm{~cm} \text { soil depth and a conventional seeder sowed seeds. }\end{array}$ \\
\hline
\end{tabular}

\subsection{Determination of soil penetration resistance}

SPR data were collected before the maize harvest in October 2019 at the fifth year of the experiment. There was no rainfall for five consecutive days before the SPR measurements were taken, with the focus on the ultimate effect of the SPR under different treatments. Therefore, the analysis of the SPR data was not 
adjusted for covariates using soil water content data. The equipment to collect SPR values included a penetrologger (Eijkelkamp PV6.08, Netherlands) with a test precision of $0.1 \mathrm{MPa}$, cone, probing rod, battery charger, etc. Three cross-sections with the same space along the diagonal direction were selected in each plot and the measurement depth was $80 \mathrm{~cm}$. The center measuring point of each cross-section was located at the middle line between two seedling strips. Other measuring points were symmetrically set every $10 \mathrm{~cm}$ on both sides ${ }^{[27,28]}$. Each cross section was $80 \mathrm{~cm}$ wide with a total of 9 measuring points for all treatments. The test rod of the penetrologger was pushed vertically downward with a constant speed of approximately $5 \mathrm{~cm} / \mathrm{s}$ and the SPR data were automatically collected at each $1 \mathrm{~cm}$ interval.

\subsection{Statistical analysis}

The SPR values were averaged in different soil depths at each profile to minimize the error caused by the uneven distribution of soil characteristics. The soil layer depths were divided into 0$15 \mathrm{~cm}, 15-30 \mathrm{~cm}, 30-45 \mathrm{~cm}, 45-60 \mathrm{~cm}$, and $60-80 \mathrm{~cm}$. R Software (Version 3.6.2) was used for the statistical analysis. The "Independent Sample $T$-test" was used to test whether there was a significant difference between the two crop residue managements under the same tillage practice. The least significant difference (LSD) and Dunnett were used for multiple comparisons when the variances were equal and unequal, respectively.

\section{Results}

\subsection{Effects of crop residue managements on soil penetration resistance}

Visualization figures of the SPR were obtained by averaging the data of repeated cross section measurements in each treatment.
Variations of the SPR at the cross sections using different crop residue managements under three tillage practices are shown in Figures $2 \mathrm{a}, 2 \mathrm{~b}, 2 \mathrm{~d}, 2 \mathrm{e}, 2 \mathrm{~g}$, and $2 \mathrm{~h}$. A comparison of the average SPR values obtained from two crop residue managements in each soil layer depth under the same tillage practice is presented in Figures $2 \mathrm{c}, 2 \mathrm{f}$, and $2 \mathrm{i}$. The results showed that crop residue managements had significant effects on SPR in some soil depths under each tillage practice. The effect of different crop residue managements showed a similar SPR trend as the soil depth increased under the same tillage practice.

Under NT treatment, the SPR value of removed crop residues was $19.2 \%$ higher than that of mulched crop residues in $0-15 \mathrm{~cm}$ topsoil depth. However, in $15-80 \mathrm{~cm}$ soil depth, the effects of crop residue managements did not demonstrate a significant effect on the SPR, as shown in Figure 2c. Under RT treatment, the effect of crop residue managements on the SPR was not significant at $0-15 \mathrm{~cm}$ soil depth. In addition, the SPR value of shallow mixed crop residues was $15.2 \%$ higher than that of removed crop residues in 15-30 cm soil depth. Although the effects of crop residue managements on the SPR were not statistically different in 30-80 $\mathrm{cm}$ soil depth, shallow mixed crop residues slowed the increasing trend of the SPR as the soil depth deepened, as shown in Figure 2f. Under PT treatment, the SPR between different crop residue managements was significantly different in all soil layers. The SPR value of deep buried crop residues was $20.8 \%$ higher than that of removed crop residues in $0-15 \mathrm{~cm}$ soil depth. Conversely, the SPR values of removed crop residues were $12.5 \%$, $15.3 \%, 23.1 \%$, and $14.0 \%$ higher than those of deep buried crop residues in $15-30 \mathrm{~cm}, 30-45 \mathrm{~cm}, 45-60 \mathrm{~cm}$, and $60-80 \mathrm{~cm}$ soil depths, respectively, as shown in Figure $2 \mathrm{i}$.

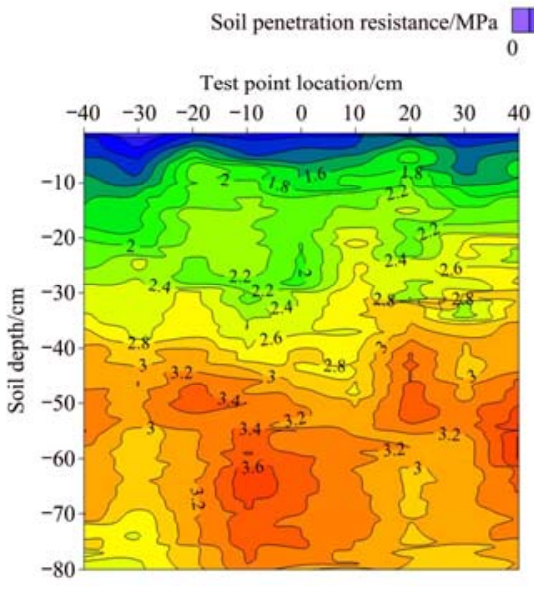

a. NT+REM

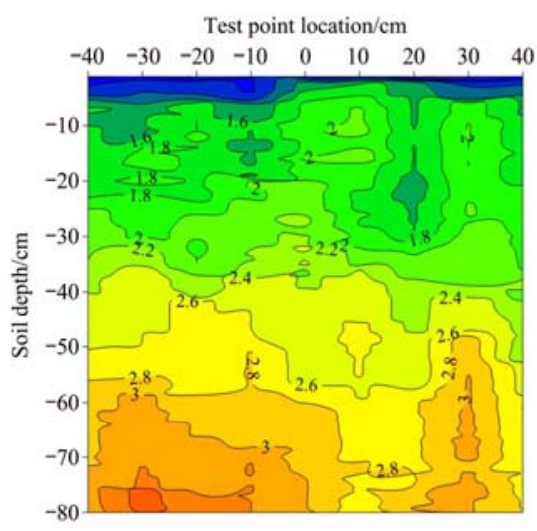

d. RT+REM

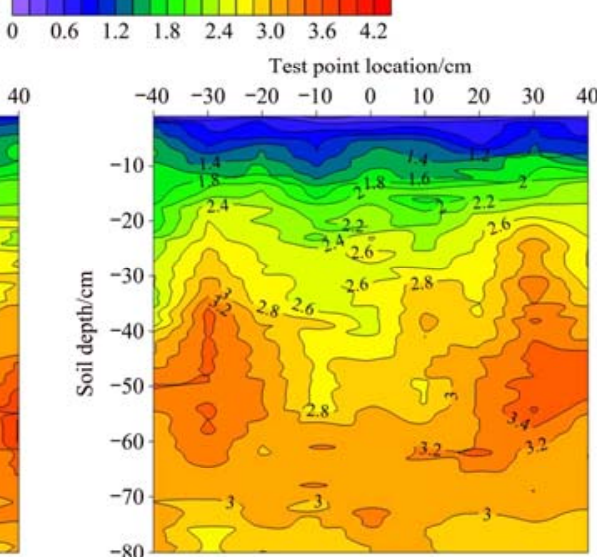

b. NT+RET

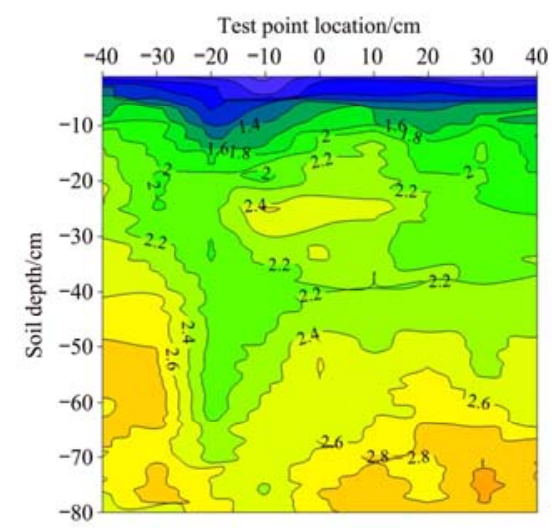

e. $R T+R E T$

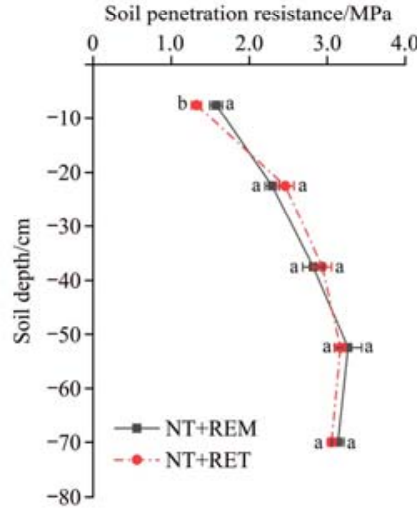

c. Variations of the average SPR values with crop residue managements under NT treatment

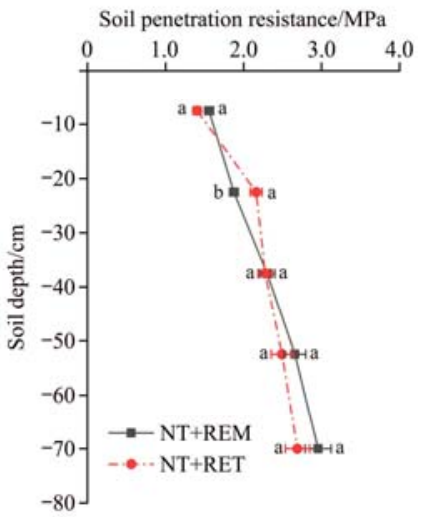

f. Variations of the average SPR values with crop residue managements under $\mathrm{RT}$ treatment 


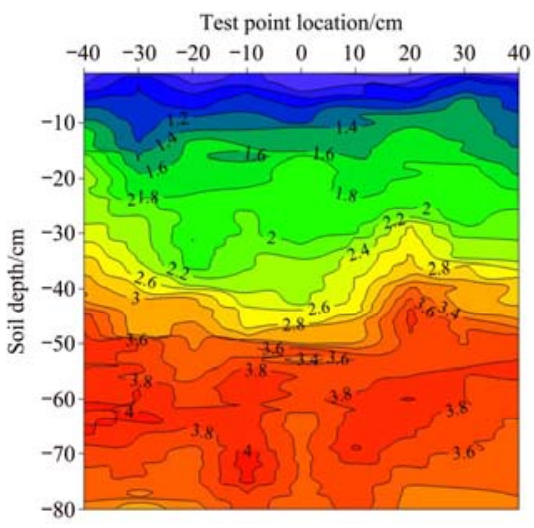

g. PT + REM

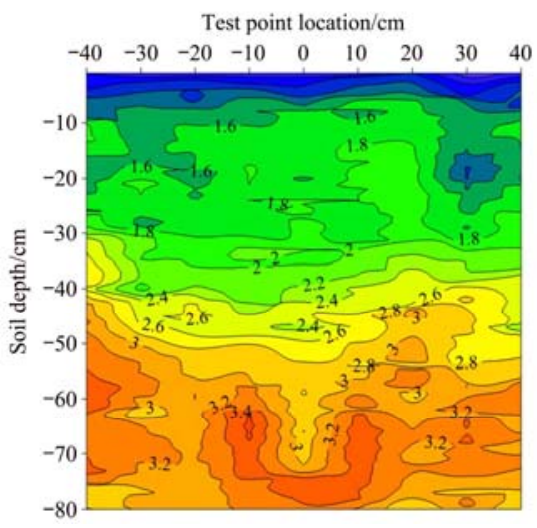

h. PT+RET

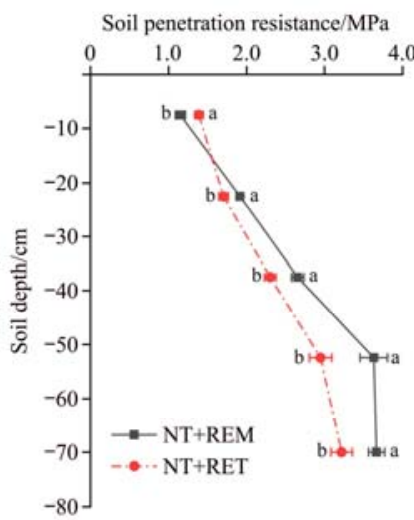

i. Variations of the average SPR values with crop residue managements under PT treatment

Note: Error bar represents mean \pm standard error, the same lowercase refers to no significant difference at 0.05 levels.

Figure 2 Variations of the SPR using two crop residue managements under each tillage practice

\subsection{Effects of tillage practices and crop residue managements on soil penetration resistance}

Effects of tillage practices and crop residue managements on the SPR were analyzed in each soil layer depth and the results are listed in Table 3. This statistical approach was similar to the method used by Zhao et al. ${ }^{[29]}$ to evaluate the effects of tillage practices and crop residue managements on soil respiration and its mechanism. The results indicate that the SPR generally increased as the depth of soil layer increased, regardless of tillage practices and crop residue managements. In comparison with RET treatment, the average SPR values for the three tillage practices under REM treatment were $10.9 \%$ and $8.9 \%$ higher in $45-60 \mathrm{~cm}$ and $60-80 \mathrm{~cm}$ soil depths, respectively. Different crop residue managements did not show a significant effect on the SPR in 0-45 $\mathrm{cm}$ soil depth. The average values of the SPR in $0-15 \mathrm{~cm}$ soil depth under NT treatment were $1.3 \%$ and $37.0 \%$ higher than RT and PT treatments for removed crop residue, respectively.

Table 3 Effects of tillage practices and crop residue managements on the SPR in each soil layer depth

\begin{tabular}{|c|c|c|c|c|c|}
\hline \multirow{2}{*}{$\begin{array}{l}\text { Depth } \\
\text { /cm }\end{array}$} & \multirow{2}{*}{ Treatment } & \multicolumn{4}{|c|}{ Soil penetration resistance/MPa } \\
\hline & & NT & RT & PT & $\begin{array}{c}\text { Average of tillage } \\
\text { practices }\end{array}$ \\
\hline \multirow{3}{*}{$0-15$} & REM & $1.576^{\mathrm{a}}$ & $1.556^{\mathrm{ab}}$ & $1.150^{\mathrm{d}}$ & $1.427^{\mathrm{a}}$ \\
\hline & RET & $1.322^{\mathrm{cd}}$ & $1.402^{\mathrm{bc}}$ & $1.389^{\mathrm{bc}}$ & $1.371^{\mathrm{a}}$ \\
\hline & $\begin{array}{l}\text { Average of crop } \\
\text { residue managements }\end{array}$ & $1.449^{\mathrm{a}}$ & $1.479^{\mathrm{a}}$ & $1.270^{\mathrm{b}}$ & \\
\hline \multirow{3}{*}{$15-30$} & REM & $2.294^{\mathrm{ab}}$ & $1.876^{\mathrm{c}}$ & $1.916^{\mathrm{c}}$ & $2.029^{a}$ \\
\hline & RET & $2.463^{\mathrm{a}}$ & $2.161^{\mathrm{b}}$ & $1.703^{\mathrm{c}}$ & $2.109^{\mathrm{a}}$ \\
\hline & $\begin{array}{l}\text { Average of crop } \\
\text { residue managements }\end{array}$ & $2.379^{\mathrm{a}}$ & $2.019^{b}$ & $1.810^{c}$ & \\
\hline \multirow{3}{*}{$30-45$} & REM & $2.821^{\mathrm{a}}$ & $2.304^{\mathrm{b}}$ & $2.655^{\mathrm{a}}$ & $2.593^{\mathrm{a}}$ \\
\hline & RET & $2.936^{\mathrm{a}}$ & $2.276^{\mathrm{b}}$ & $2.303^{\mathrm{b}}$ & $2.505^{\mathrm{a}}$ \\
\hline & $\begin{array}{l}\text { Average of crop } \\
\text { residue managements }\end{array}$ & $2.879^{\mathrm{a}}$ & $2.290^{b}$ & $2.479^{b}$ & \\
\hline \multirow{3}{*}{$45-60$} & REM & $3.267^{\mathrm{ab}}$ & $2.657^{\text {cd }}$ & $3.629^{\mathrm{a}}$ & $3.184^{a}$ \\
\hline & RET & $3.169^{\mathrm{b}}$ & $2.493^{\mathrm{d}}$ & $2.949^{\mathrm{bc}}$ & $2.870^{b}$ \\
\hline & $\begin{array}{l}\text { Average of crop } \\
\text { residue managements }\end{array}$ & $3.218^{\mathrm{a}}$ & $2.575^{\mathrm{b}}$ & $3.289^{\mathrm{a}}$ & \\
\hline \multirow{3}{*}{$60-80$} & REM & $3.136^{\mathrm{b}}$ & $2.955^{\mathrm{b}}$ & $3.667^{\mathrm{a}}$ & $3.253^{\mathrm{a}}$ \\
\hline & RET & $3.055^{\mathrm{b}}$ & $2.691^{\mathrm{b}}$ & $3.218^{\mathrm{ab}}$ & $2.988^{b}$ \\
\hline & $\begin{array}{l}\text { Average of crop } \\
\text { residue managements }\end{array}$ & $3.096{ }^{b}$ & $2.823^{b}$ & $3.443^{\mathrm{a}}$ & \\
\hline
\end{tabular}

$\overline{\text { Note: NT: No tillage; RT: Rotary tillage; PT: Plow tillage; REM: Crop residues }}$ removed; RET: Crop residues retained. The same lowercase after data in the same group refers to no significant difference at 0.05 levels.
However, the difference was not significant for retained crop residue. The average SPR value for the two crop residue managements under PT treatment was $11.2 \%$ and $22.0 \%$ higher in $60-80 \mathrm{~cm}$ soil depth than the ones under NT and RT treatments, respectively. In addition, the average values of the SPR under PT treatment were lower by $12.4 \%$ and $14.1 \%$ in $0-15 \mathrm{~cm}$ depth and $23.9 \%$ and $10.4 \%$ in the $15-30 \mathrm{~cm}$ soil depth than those under NT and RT treatments, respectively. The results revealed that the SPR of PT treatment increased more obviously than that of NT and RT treatments as the soil depth deepened, especially in the case of removed crop residues.

\subsection{Effects of slope positions on soil penetration resistance}

Figures 3 and 4 show that as the soil depth deepened, the SPR generally decreased with the slope position declined (except for the NT+RET treatment). Overall, the SPR value at the same slope position had a positive-linear relationship with the soil layer depth, as shown in Figure 3. The relationship between the SPR value and soil layer depth in each treatment was generally significant. However, non-significant results were found at the middle and lower plot positions under NT+RET treatment and the lower plot position under RT+RET treatment. The coefficient of determination $\left(R^{2}\right)$ of each treatment varied with slope positions in $0-80 \mathrm{~cm}$ soil depth. Comparing the $R^{2}$ of three slope positions under each tillage practice, the overall maximum $R^{2}$ values were achieved under PT treatment $\left(R^{2}>0.85\right)$, followed by RT treatment $\left(R^{2}>0.70\right)$. The minimum value was achieved under NT treatment $\left(R^{2}>0.50\right)$. Regression models demonstrated that retained crop residues slowed the increase of the SPR as the soil depth deepened at each slope position treated by RT and PT treatments, as shown in Figure 3.

The effect of tillage practices and crop residue managements on the SPR at each slope position was different as the soil depth deepened, as shown in Figure 4. Under the condition of removed crop residues, there were no significant differences among slope positions only in $0-15 \mathrm{~cm}$ and $15-30 \mathrm{~cm}$ soil depths under RT and PT treatments, respectively. The maximum variation in the SPR among slope positions under NT treatment was in 45-60 cm soil depth, and the SPR value of the upper slope was $22.6 \%$ and $41.7 \%$ higher than those of the middle and lower slopes, respectively. The maximum variation under RT treatment was in $60-80 \mathrm{~cm}$ soil depth, and the SPR value of the upper slope was $0.9 \%$ and $43.3 \%$ higher than those of the middle and lower slopes, respectively. There was no significant difference between the upper and middle 
slopes. The maximum variation under PT treatment was in 45-60 $\mathrm{cm}$ soil depth, and the SPR value of the upper slope was $14.6 \%$ and

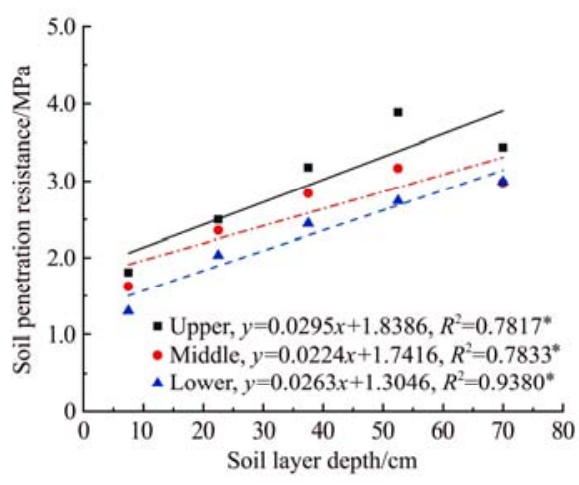

a. NT+REM

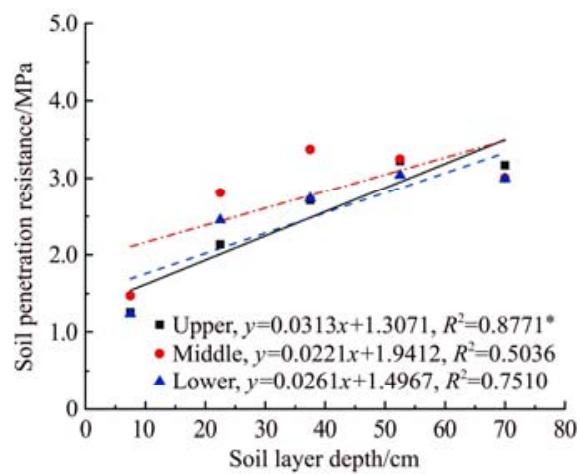

d. NT+RET

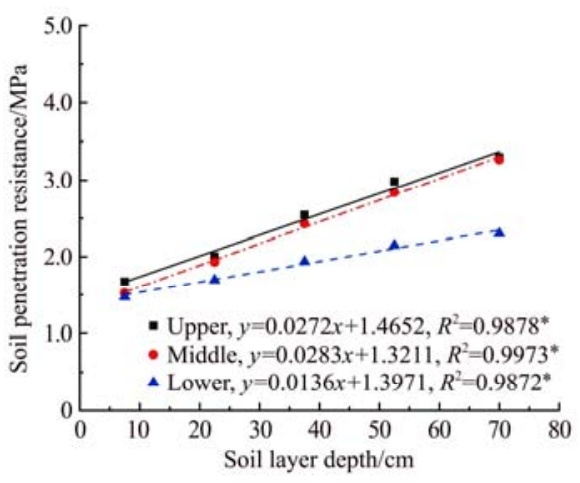

b. RT+REM

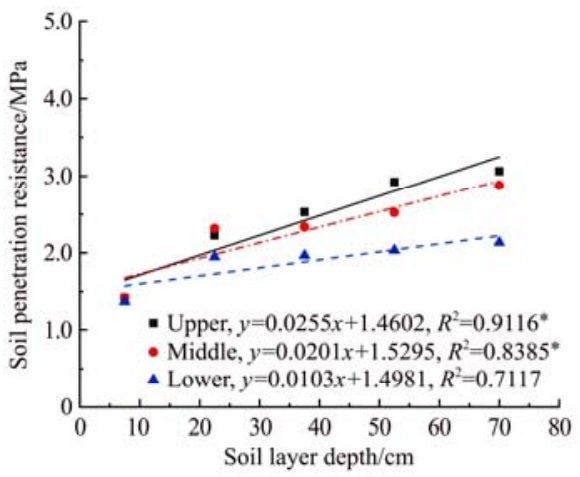

e. RT+RET

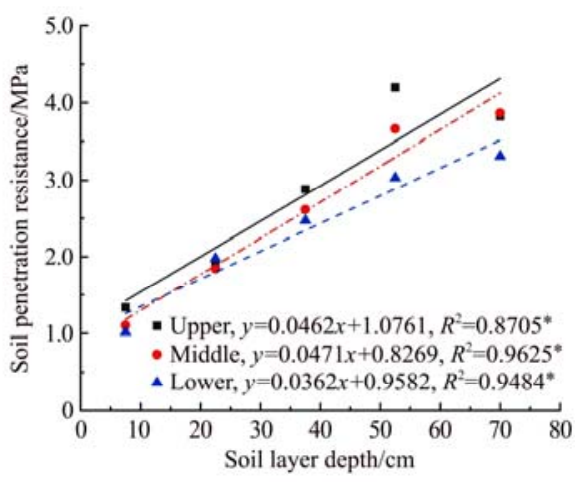

c. PT+REM

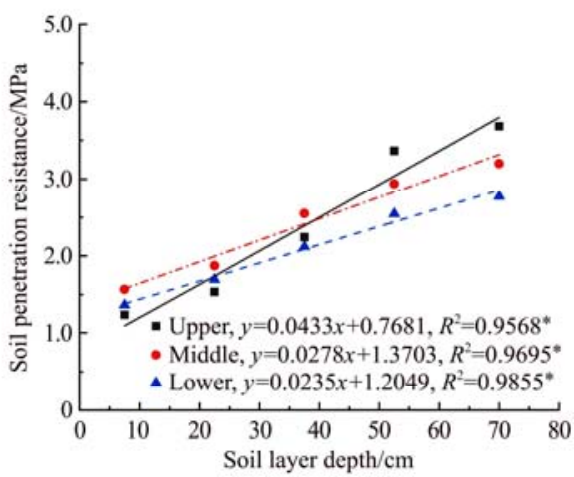

f. PT+RET

Note: * indicates significant difference at 0.05 levels.

Figure 3 Relationship between the SPR value and the soil layer depth at three slope positions

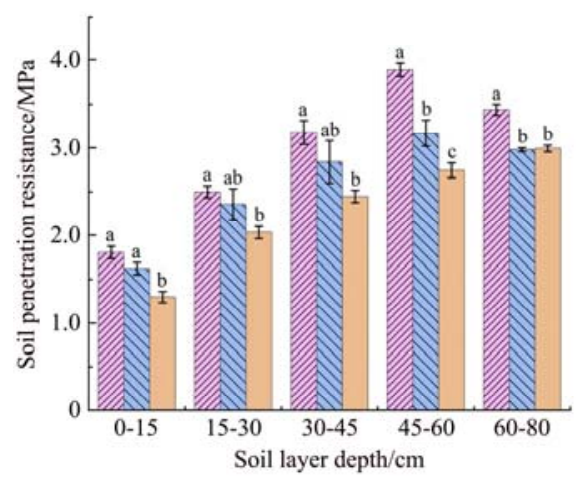

a. NT+REM

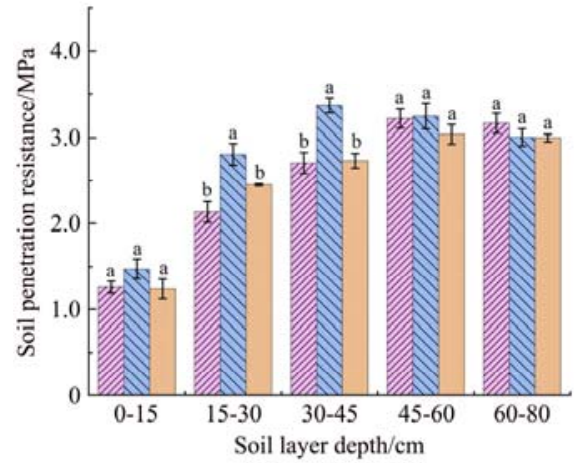

d. NT+RET

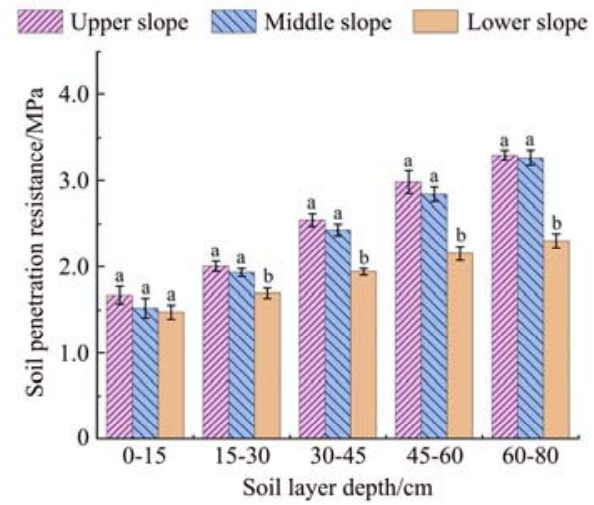

b. RT+REM

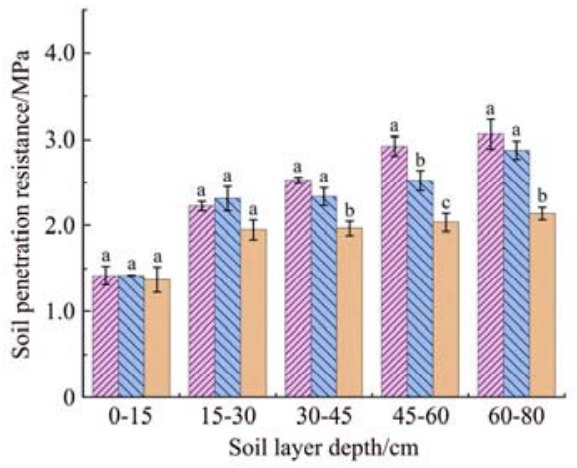

e. RT+RET

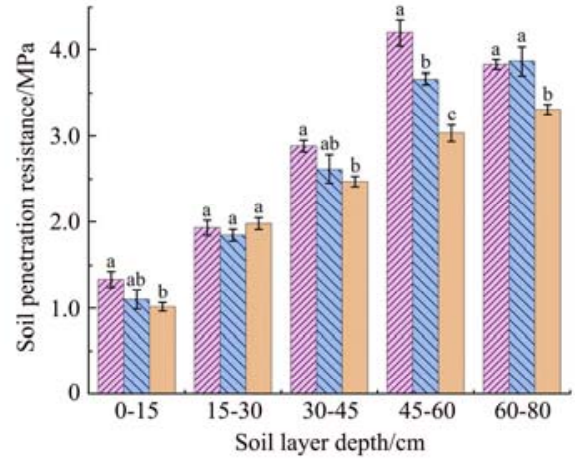

c. PT+REM

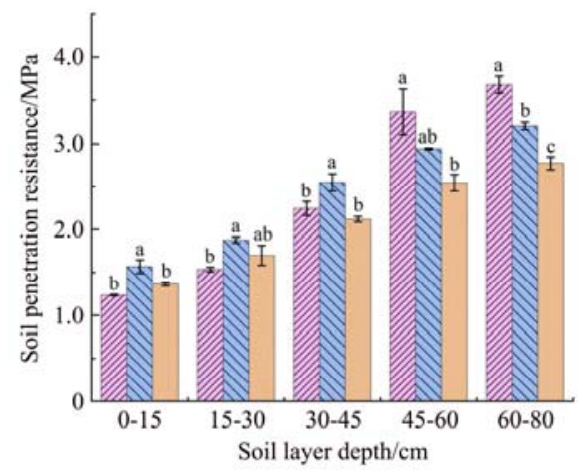

f. PT+RET

Note: Error bar represents mean \pm standard error, the same lowercase refers to no significant difference at 0.05 levels.

Figure 4 Comparison of the SPR value among different slope positions in each treatment

Under the condition of retained crop residues, there were no significant differences among slope positions in $0-15 \mathrm{~cm}$ and $45-$ $80 \mathrm{~cm}$ soil depths under NT treatment and 0-30 $\mathrm{cm}$ soil depth under
RT treatment. The maximum difference in the SPR among slope positions under NT treatment was in $15-30 \mathrm{~cm}$ soil depth, and the SPR value of the middle slope was $31.6 \%$ and $14.6 \%$ higher than 
those of the upper and lower slopes, respectively. The maximum difference under RT treatment was in 45-60 cm soil depth, and the SPR value of the upper slope was $15.8 \%$ and $43.6 \%$ higher than those of the middle and lower slopes, respectively. The maximum variation under PT treatment was in $60-80 \mathrm{~cm}$ soil depth, and the SPR value of the upper slope was $15.1 \%$ and $32.8 \%$ higher than those of the middle and lower slopes, respectively.

\section{Discussion}

\subsection{Effects of crop residue managements on soil penetration resistance}

Results of the present study indicate that the effects of crop residue managements on the SPR varied with differences in tillage practice. The difference may be related to tillage practice, and tillage practice may directly influence the soil structure as well as degree of fragmentation and distribution of the crop residues in the crop field ${ }^{[30]}$.

It was also found that compared with removed crop residues, NT+RET treatment significantly decreased the SPR in the $0-15 \mathrm{~cm}$ surface soil depth with no significant difference below the surface depth. Similar results were reported under the no-till treatment, where the near-surface soil depth with covered crops and retained residues generally had a low $\mathrm{SPR}^{[1,17,31]}$. This phenomenon can be explained because bare soil mulched by crop residues effectively reduces soil exposure and alleviates the impact of multiple compactions of operation machinery in topsoil. In addition, crop residue mulching on the soil surface could intercept the effects of wind and raindrops, thereby decreasing soil erosion and maintaining soil surface structure ${ }^{[15,20,30]}$. The research by Colombi et al. ${ }^{[4]}$ showed that approximately $57 \%$ to $71 \%$ of the total root biomass of maize was found in the top $12.5 \mathrm{~cm}$ soil depth under no-till treatment, indicating that physical properties in the topsoil depth play an important role in root growth. Therefore, NT treatment with retained crop residue creates a more suitable condition in the surface soil depth for the root growth of maize.

The present study found that shallow mixed crop residues under RT treatment alleviated compactness and decreased the SPR in the surface $0-15 \mathrm{~cm}$ soil depth, although the difference was not significant. A similar result was reported by Singh and Malhi ${ }^{[32]}$. However, the effect of shallow mixed crop residues on the SPR in the $0-15 \mathrm{~cm}$ soil depth was less than that of surface mulched. This might be attributed to the fact that the crop residues on the soil surface decomposed less rapidly and mulched crop residues could contribute to protecting soil physical properties for a longer period $^{[33]}$. In addition, crop residues were distributed relatively homogeneously in the tilled layer under RT+RET treatment, which significantly increased the SPR in $15-30 \mathrm{~cm}$ soil depth. The negative effect may be related to the high total soil porosity caused by soil disturbance combined with crop residues mixed in the tilled layer, which reduces the ability of the surface soil layer to resist compaction. Consequently, the kinetic energy of rain, which mostly occurs in the topsoil layer, is transferred to the soil below the tilled layer, although the influence depth is limited ${ }^{[34,35]}$.

Compared with removed crop residues, there was a significant increase of the SPR in $0-15 \mathrm{~cm}$ soil depth and a significant reduction of the SPR in $15-80 \mathrm{~cm}$ soil depth using the PT+RET treatment. This result is mainly due to the isolated region formed by crop residues accumulated during the ploughing operation in the tilled layer. The decomposition of crop residues in the isolated region is limited because of less contact between the soil and crop residues $^{[36]}$. The isolation effect of crop residues presented in
15-30 cm soil depth for long-term would make soil compaction due that cultivation and erosion mainly acted in the thin topsoil layer, and this negative effect was intensified ${ }^{[37]}$. The aggregation of crop residues and soil could maintain voids between aggregates and clods, which reduced the soil density in $15-30 \mathrm{~cm}$ soil depth and relieved the compaction effect in the deeper soil layer ${ }^{[6,38]}$. In addition, the tillage depth of loose soil was limited and crop residues effectively decreased the SPR in the plow pan under PT treatment, which could not be remediated by the ploughing operation.

\subsection{Effects of tillage practices and crop residue managements} on soil penetration resistance

Both tillage practices and crop residue managements had significant effects on the SPR on sloping land. The high dependence of the SPR on soil depths, tillage practices, and crop residue managements has been widely recognized ${ }^{[1,18,24]}$. Our findings suggested that RET treatment significantly decreased the average values of the SPR for tillage practices in the $45-80 \mathrm{~cm}$ soil depth, while the SPR variation between REM and RET treatments was not significant in the $0-45 \mathrm{~cm}$ soil depth. As mentioned above, the presence of crop residues could reduce the negative effect, relieve the transfer effect of compaction, and provide moist soil condition. Therefore, the increase of the SPR in the deep soil depth was mitigated regardless of whether the crop residues were mulched, shallowly mixed, or deep buried. However, the differences were not always significant under various tillage practices.

Many studies have indicated that the SPR under the no-tilled practice is higher than that under the tilled practice. The soil disturbance caused by the tillage operation destroyed soil aggregates and thus decreased the $\operatorname{SPR}^{[1,7,39]}$. Results of the present research also indicated this phenomenon in $0-15 \mathrm{~cm}$ soil depth for removed crop residues. However, no significant difference was found between no-tilled and tilled practices in the surface layer for retained crop residues. The reason for this phenomenon can be explained by the interaction of crop residue managements and tillage practices ${ }^{[23]}$. Previous studies demonstrated that traffic and compaction of working machinery wheels were absorbed and weakened by crop covering, which also provided wetter soil conditions ${ }^{[6,40]}$. Cassel et al. ${ }^{[41]}$ found that the SPR was not affected by tillage practices under the condition of retained crop residues, as the mechanical disruption was short-lived on bare soil and the surface seal was reformed by moderate or intense rainfall.

A significant increase of the SPR under PT treatment was observed as the soil depth deepened, especially for removed crop residues. Although there was a loosening effect in the disturbed soil layer under the tillage operation, the tillage effect might be extended to undisturbed soil layers. This may be because the PT treatment resulted in more serious compaction of soil and the pressure wave from machine traffic and cultivation could affect the soil up to a depth of $65-80 \mathrm{~cm}^{[27]}$. PT treatment for five years induced a plough pan below the ploughing soil. The compacted layer increased over time, extending to a deeper soil depth. The inhibitions of water infiltration and root penetration in the plough pan were not conducive to the alleviation of SPR in the deep soil $\mathrm{depth}^{[42]}$. Previous studies showed that excessive tillage practices broke the compactness and disrupted the soil aggregates of the tilled soil layer, yet caused denser compactness in the region below the tilled layer ${ }^{[18,42]}$. A study conducted by Kabiri et al. ${ }^{[11]}$ showed that soil density was higher under an inversion tillage treatment, 
which was most likely due to the significant disruption of soil macroaggregates and subsequent compaction in the surface layer. Minimized tillage disturbance and mulched or mixed crop residues could increase the organic carbon pool and biodiversity of the soil and stabilize soil aggregates, thus providing a positive effect on the soil quality in the deep layer ${ }^{[20,43]}$.

\subsection{Effects of slope positions on soil penetration resistance}

The SPR generally decreased as the slope position declined, irrespective of tillage practices and crop residue managements, indicating that differences of the SPR could be induced by spatial variability. This result was consistent with Jung et al. ${ }^{[44]}$, who reported that the SPR was not only affected by vehicular traffic, plant residue, tillage, and rotation but also by the landscape position and their interactions. The linear regression results showed that the SPR increased more significantly as the soil depth deepened at the upper slope under PT treatment, suggesting that heavy tillage might worsen the soil condition, especially at the upper slope ${ }^{[6]}$.

Researches have indicated that NT treatment increased aggregate stability and ensured less slaking on sloping land due to undisturbed soil ${ }^{[16,32]}$. In addition, NT treatment has demonstrated effectiveness in controlling soil erosion and runoff, increasing water infiltration, enhancing the concentration of soil organic matter, improving soil biological activity, and saving energy ${ }^{[19,45]}$. However, our results indicated that NT treatment combined with mulched crop residues was more stable to the response of spatial variation of the SPR, reducing the process of soil degradation and improving soil quality ${ }^{[46]}$. Gholami et al. ${ }^{[15]}$ verified that mulched crop residues on sloping land protected soil surface aggregates from the direct impact energy of raindrops, prevented soil detachment, and increased surface roughness, which maintained soil surface structure and reduced splash erosion and runoff. Previous studies also demonstrated that no tillage and retained crop residues increased contents of soil organic carbon and total nitrogen in the soil macroaggregates, and the addition of organic matter improved soil aggregation processes as a result of the organic matter acting as a binding agent for soil aggregation ${ }^{[47,48]}$.

There was no significant difference among the three slope positions in the $0-30 \mathrm{~cm}$ soil depth under RT+RET treatment. This result was consistent with the recent study conducted by Yan et al. ${ }^{[26]}$, which demonstrated that NT treatment was better than RT treatment in the maintenance of soil structure on hillslope cropland. Blanco-Canqui and Ruis ${ }^{[49]}$ reported that even slight or shallow disturbance might adversely affect the stability of the soil structure. In this study, it was also confirmed by the variation of the SPR under tillage practices on the sloping land, while shown in the deep soil layer. In addition, RT+RET treatment resulted in less disruption than PT treatment and greater surface roughness than soil exposure. Additionally, the high contact area between the soil and crop residues in the topsoil layer caused higher availability of soil organic matter ${ }^{[36]}$. As a consequence, these conditions improved the stability of soil aggregates and decreased soil erosion in the shallow layer on the sloping land ${ }^{[35,36,50]}$.

The slope position had significant effects on the SPR in each soil layer depth under PT treatment, even after the residues were retained in the field. Some research indicates that there is high variability in soil physical properties under the ploughing operation. This is because deep tillage breaks the soil pore continuities and destroys large soil aggregates, thereby increasing the likelihood of particle slaking and pore clogging ${ }^{[16,38]}$. The bare and loose soil under the intensive tillage encountered more serious soil erosion on the sloping land whether the crop residues were retained or not, which led to a decrease in the stability of the soil structure ${ }^{[19,42]}$. In addition, the increase of soil roughness and looseness caused by tillage showed a limited duration, and the bare soil promoted new surface crust and recompaction. This intensified the runoff from the upper to lower slope and greatly reduced the water infiltration of the sloping land ${ }^{[51]}$. As a consequence, the difference of the SPR among various slope positions was further increased due to different soil water contents ${ }^{[9]}$. In comparison with removed crop residues, deep buried crop residues under PT treatment not only reduced the SPR in the deep soil layer, but also decreased the maximum difference of the SPR among slope positions by $21.6 \%$ (from 1.16 to $0.91 \mathrm{MPa}$ ). Deep buried crop residues under PT treatment showed higher concentrations of soil organic carbon and total nitrogen, and enhanced activities of various soil macro- and micro-organisms, which helped to improve the stability of soil aggregates below the tillage region ${ }^{[42,48]}$.

\section{Conclusions}

This research evaluated the effects of two crop residue managements and three tillage practices on the SPR under different slope positions. Our findings suggested that the direct influences of tillage practices on the diverse distributions of crop residues and soil structures led to differences in the SPR. Residue managements had significant effects on the SPR under NT, RT, and PT treatments for the soil depths of $0-15 \mathrm{~cm}, 15-30 \mathrm{~cm}$, and 0 $80 \mathrm{~cm}$, respectively. In general, retained crop residues exhibited an alleviated effect on the increase of the SPR as the soil depth deepened. In comparison with RET treatment, the average values of the SPR under REM treatment were $10.9 \%$ and $8.9 \%$ higher in $45-60 \mathrm{~cm}$ and $60-80 \mathrm{~cm}$ soil depths, respectively. The increase of SPR with PT practice was higher than that with NT and RT practices as the soil depth deepened, especially for removed crop residue. The SPR generally showed a decreasing trend with the decline of slope position as the soil depth deepened, regardless of the crop residue managements or tillage practices. The sensitivity of NT+RET treatment dramatically declined with varied slope positions.

\section{Acknowledgements}

This work was financially supported by the Special Fund Project for the Construction of Modern Agricultural Industrial Technology System of China (Grant No. CARS-04).

\section{[References]}

[1] Tormena C A, Karlen D L, Logsdon S, Cherubin M R. Corn stover harvest and tillage impacts on near-surface soil physical quality. Soil Tillage Res, 2017; 166: 122-130.

[2] Crittenden S J, Poot N, Heinen M, van Balen D J M, Pulleman M M. Soil physical quality in contrasting tillage systems in organic and conventional farming. Soil Tillage Res, 2015; 154: 136-144.

[3] He Y B, Lin L R, Chen J Z. Maize root morphology responses to soil penetration resistance related to tillage and drought in a clayey soil. J Agric Sci, 2017; 155(7): 1137-1149.

[4] Colombi T, Torres L C, Walter A, Keller T. Feedbacks between soil penetration resistance, root architecture and water uptake limit water accessibility and crop growth-A vicious circle. Sci Total Environ, 2018; 626: 1026-1035.

[5] Guedes O, Silva A P, Giarola N F B, Tormena C A, Mazzini-Guedes RB. Boundary line approach applied among crop emergence parameters and soil physical properties. Rev Bras Eng Agric Ambient, 2019; 23(6): 454-459.

[6] Shah A N, Tanveer M, Shahzad B, Yang G Z, Fahad S, Ali S, et al. Soil compaction effects on soil health and crop productivity: An overview. Environ Sci Pollut Res, 2017; 24(11): 10056-10067. 
[7] Salem H M, Valero C, Munoz M A, Rodriguez M G, Silva L L. Short-term effects of four tillage practices on soil physical properties, soil water potential, and maize yield. Geoderma, 2015; 237: 60-70.

[8] Lapen D R, Topp G C, Edwards M E, Gregorich E G, Curnoe W E. Combination cone penetration resistance/water content instrumentation to evaluate cone penetration-water content relationships in tillage research. Soil Tillage Res, 2004; 79(1): 51-62.

[9] Vaz C M P, Manieri J M, de Maria I C, Tuller M. Modeling and correction of soil penetration resistance for varying soil water content. Geoderma, 2011; 166(1): 92-101.

[10] Zhang X H, Lu Y, Wang Q G, Qian X. A high-resolution inventory of air pollutant emissions from crop residue burning in China. Atmos Environ, 2019; 213: 207-214.

[11] Kabiri V, Raiesi F, Ghazavi M A. Six years of different tillage systems affected aggregate-associated SOM in a semi-arid loam soil from Central Iran. Soil Tillage Res, 2015; 154: 114-125.

[12] Lindstrom M J. Effects of residue harvesting on water runoff, soil erosion and nutrient loss. Agriculture, Ecosystems \& Environment, 1986; 16(2): $103-112$.

[13] Chen L, Zhang J B, Zhao B Z, Yan P, Zhou G X, Xin X L. Effects of straw amendment and moisture on microbial communities in Chinese fluvo-aquic soil. Journal of Soils and Sediments, 2014; 14(11): 1829-1840.

[14] Li Y, Chen H, Feng H, Dong Q G, Wu W J, Zou Y F, et al. Influence of straw incorporation on soil water utilization and summer maize productivity: A five-year field study on the Loess Plateau of China. Agricultural Water Management, 2020; 233: 106106. doi: 10.1016/j.agwat.2020.106106.

[15] Gholami L, Sadeghi S H, Homaee M. Straw mulching effect on splash erosion, runoff, and sediment yield from eroded plots. Soil Sci Soc Am J, 2013; 77(1): 268-278.

[16] Mitchell J P, Shrestha A, Mathesius K, Scow K M, Southard R J, Haney R L, et al. Cover cropping and no-tillage improve soil health in an arid irrigated cropping system in California's San Joaquin Valley, USA. Soil Tillage Res, 2017; 165: 325-335.

[17] Chalise K S, Singh S, Wegner B R, Kumar S, Perez-Gutierrez J D, Osborne $\mathrm{S} \mathrm{L}$, et al. Cover crops and returning residue impact on soil organic carbon, bulk density, penetration resistance, water retention, infiltration, and soybean yield. Agron J, 2019; 111(1): 99-108.

[18] Mu X Y, Zhao Y L, Liu K, Ji B Y, Guo H B, Xue Z W, et al. Responses of soil properties, root growth and crop yield to tillage and crop residue management in a wheat-maize cropping system on the North China Plain. Eur J Agron, 2016; 78: 32-43.

[19] Lal R, Reicosky D L, Hanson J D. Evolution of the plow over 10,000 years and the rationale for no-till farming. Soil Tillage Res, 2007; 93(1): 1-12.

[20] Bronick C J, Lal R. Soil structure and management: a review. Geoderma, 2005; 124(1-2): 3-22.

[21] Chen S, Burras C L, E L L, Zhang X Y. Interrelationship among slope steepness, tillage practice and rainfall properties with surface runoff and soil loss on Mollisols in Northeast China. Arch Agron Soil Sci, 2019; 65(13): $1860-1872$

[22] Yang W G, Han Y, Zheng F L, Wang Z L, Yi Y, Feng Z Z. Investigating spatial distribution of soil quality index and its impacts on corn yield in a cultivated catchment of the Chinese mollisol region. Soil Sci Soc Am J, 2016; 80(2): 317-327.

[23] Villamil M B, Little J, Nafziger E D. Corn residue, tillage, and nitrogen rate effects on soil properties. Soil Tillage Res, 2015; 151: 61-66.

[24] Fashi F H, Gorji M, Sharifi F. Temporal variability of soil water content and penetration resistance under different soil management practices. J Soil Water Conserv, 2019; 74(2): 188-198.

[25] Jonard F, Mahmoudzadeh M, Roisin C, Weihermuller L, Andre F, Minet J, et al. Characterization of tillage effects on the spatial variation of soil properties using ground-penetrating radar and electromagnetic induction. Geoderma, 2013; 207: 310-322.

[26] Yan L, Jiang X X, Ji X N, Zhou L T, Li S Y, Chen C, et al. Distribution of water-stable aggregates under soil tillage practices in a black soil hillslope cropland in Northeast China. J Soils Sediments, 2020; 20(1): 24-31.

[27] Qiao J Y, Zhang D, Zhang H B, Zhang B, Chen H T, Chen L P, et al. Effects of soil compaction by various tractors on soil penetration resistance and soybean yields. Transactions of the CSAE, 2019; 35(21): 26-33. (in Chinese)

[28] Chen X W, Fan R Q, Shi X H, Liang A Z, Zhang X P, Jia S X. Spatial variation of penetration resistance and water content as affected by tillage and crop rotation in a black soil in Northeast China. Acta Agric Scand Sect
B-Soil Plant Sci, 2013; 63(8): 740-747.

[29] Zhao Y L, Xue Z W, Guo H B, Mu X Y, Li C H. Effects of tillage and crop residue management on soil respiration and its mechanism. Transactions of the CSAE, 2014; 30(19): 155-165. (in Chinese)

[30] Guérif J, Richard G, Dürr C, Machet J M, Recous S, Roger-Estrade J. A review of tillage effects on crop residue management, seedbed conditions and seedling establishment. Soil Tillage Res, 2001; 61(1): 13-32.

[31] Blanco-Canqui H, Lal R, Post W M, Izaurralde RC, Owens L B. Corn stover impacts on near-surface soil properties of no-till corn in Ohio. Soil Sci Soc Am J, 2006; 70(1): 266-278.

[32] Singh B, Malhi S S. Response of soil physical properties to tillage and residue management on two soils in a cool temperate environment. Soil Tillage Res, 2006; 85(1-2): 143-153.

[33] Skidmore E L, Layton J B, Armbrust D V, Hooker M L. Soil physical properties as influenced by cropping and residue management. Soil Sci Soc Am J, 1986; 50: 415-419.

[34] Bogunovic I, Pereira P, Kisic I, Sajko K, Sraka M. Tillage management impacts on soil compaction, erosion and crop yield in Stagnosols (Croatia). Catena, 2018; 160: 376-384.

[35] Latifmanesh H, Deng A X, Li L, Chen Z J, Zheng Y T, Bao X T, et al. How incorporation depth of corn straw affects straw decomposition rate and $\mathrm{C} \& \mathrm{~N}$ release in the wheat-corn cropping system. Agriculture Ecosystems \& Environment, 2020; 300: 8. doi: 10.1016/j.agee.2020.107000

[36] Kasteel R, Garnier P, Vachier P, Coquet Y. Dye tracer infiltration in the plough layer after straw incorporation. Geoderma, 2007; 137(3-4): 360-369.

[37] Staricka J A, Allmaras R R, Nelson W W. Spatial variation of crop residue incorporated by tillage. Soil Sci Soc Am J, 1991; 55(6): 1668-1674.

[38] Alletto L, Coquet Y, Roger-Estrade J. Two-dimensional spatial variation of soil physical properties in two tillage systems. Soil Use Manage, 2010; 26(4): 432-444.

[39] Junior V V, Carvalho M P, Dafonte J, Freddi O S, Vazquez E V, Ingaramo O E. Spatial variability of soil water content and mechanical resistance of Brazilian ferralsol. Soil Tillage Res, 2006; 85(1-2): 166-177.

[40] Barbosa L C, Magalhaes P S G, Bordonal R O, Cherubin M R, Castioni GAF, Tenelli $\mathrm{S}$, et al. Soil physical quality associated with tillage practices during sugarcane planting in south-central Brazil. Soil and Tillage Research, 2019; 195: 104383. doi: 10.1016/j.still.2019.104383.

[41] Cassel D K, Raczkowski C W, Denton H P. Tillage effects on corn production and soil physical conditions. Soil Sci Soc Am J, 1995; 59: 1436-1443.

[42] Indoria A K, Rao C S, Sharma K L, Reddy K S. Conservation agriculture-a panacea to improve soil physical health. Curr Sci, 2017; 112(1): 52-61.

[43] Lal R. Restoring soil quality to mitigate soil degradation. Sustainability, 2015; 7(5): 5875-5895.

[44] Jung K Y, Kitchen N R, Sudduth K A, Lee K S, Chung S O. Soil compaction varies by crop management system over a claypan soil landscape. Soil Tillage Research, 2010; 107(1): 1-10.

[45] Nunes M R, van Es H M, Schindelbeck R, Ristow A J, Ryan M. No-till and cropping system diversification improve soil health and crop yield. Geoderma, 2018; 328: 30-43.

[46] Das A, Layek J, Idapuganti R G, Basavaraj S, Lal R, Rangappa K, et al. Conservation tillage and residue management improves soil properties under a upland rice-rapeseed system in the subtropical eastern Himalayas. Land Degradation \& Development, 2020; 31(14): 1775-1791.

[47] Wu J, Stephen Y, Cai L Q, Zhang R Z, Qi P, Luo Z Z, et al. Effects of different tillage and straw retention practices on soil aggregates and carbon and nitrogen sequestration in soils of the northwestern China. J Arid Land, 2019; 11(4): 567-578.

[48] Pu C, Kan Z R, Liu P, Ma S T, Qi J Y, Zhao X, et al. Residue management induced changes in soil organic carbon and total nitrogen under different tillage practices in the North China Plain. J Integr Agric, 2019; 18(6): 1337-1347.

[49] Blanco-Canqui H, Ruis S J. No-tillage and soil physical environment. Geoderma, 2018; 326: 164-200.

[50] D'Haene K, Vermang J, Cornelis W M, Leroy B L M, Schiettecatte W, De Neve S, et al. Reduced tillage effects on physical properties of silt loam soils growing root crops. Soil Tillage Res, 2008; 99(2): 279-290.

[51] Niziolomski J C, Simmons R W, Rickson R J, Hann M J. Efficacy of mulch and tillage options to reduce runoff and soil loss from asparagus interrows. CATENA, 2020; 191: 104557. doi: 10.1016/j.catena.2020.104557. 